\title{
Correction to: Magnetic resonance imaging features of the superior cervical ganglion and expected changes after radiation therapy to the head and neck in a long-term follow-up
}

\begin{abstract}
Marco Ravanelli ${ }^{1}$ - Elena Tononcelli ${ }^{1} \cdot$ Michela Leali $^{1} \cdot$ Irene Buffa $^{1} \cdot$ Siu Cheng Loke ${ }^{2}$ - Amit Karandikar ${ }^{2}$.

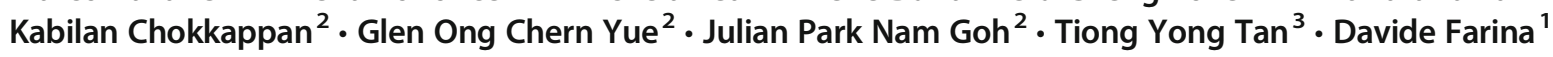

Published online: 5 April 2020

(C) Springer-Verlag GmbH Germany, part of Springer Nature 2020

Correction to: Neuroradiology (2020). https://doi.org/10.1007/s00234-020-02373-4

In the article "Magnetic resonance imaging features of the superior cervical ganglion and expected changes after radiation therapy to the head and neck in a long-term follow-up", one of the author names, K Chokkappan, was spelled incorrectly.

The corrected author list is as follows:

Ravanelli $\mathrm{M}^{1}$, Tononcelli $\mathrm{E}^{1}$, Leali $\mathrm{M}^{1}$, Buffa $\mathrm{I}^{1}$, Loke $\mathrm{SC}^{2}$, Karandikar A ${ }^{2}$, Chokkappan $\mathrm{K}^{2}$, Yue $\mathrm{GOC}^{2}$, Goh $\mathrm{JPN}^{2}$, Tan $\mathrm{TY}^{3}$, Farina $\mathrm{D}^{1}$.

The online version of the original article can be found at https://oi.org/ $10.1007 / \mathrm{s} 00234-020-02373-4$

Irene Buffa

irenebuffa89@gmail.com

Marco Ravanelli

marcoravanelli@hotmail.it

Elena Tononcelli

tononcelli.elena@gmail.com

Michela Leali

michela.leali@icloud.com

Siu Cheng Loke

siu_cheng_loke@ttsh.com.sg

Amit Karandikar

amit_karandikar@ttsh.com.sg

Kabilan Chokkappan

kabilan.chokkapan@mohh.com.sg
Glen Ong Chern Yue

glen.ong@mohh.com.sg

Julian Park Nam Goh

Julian_Goh@ttsh.com.sg

Tiong Yong Tan

tan.tiong.yong@singhealth.com.sg

Davide Farina

davide.farina@unibs.it

1 Department of Radiology, University of Brescia, Piazzale Spedali Civili 1, 25123 Brescia, Italy

2 Department of Diagnostic Radiology, Tan Tock Seng Hospital, Singapore, Singapore

3 Department of Radiology, Changi General Hospital, Singapore, Singapore 